\title{
Associations between animal traits, carcass traits and carcass classification in a selected abattoir in the Eastern Cape Province, South Africa
}

\author{
Z. Soji, S.P. Mabusela \& V. Muchenje \\ Department of Livestock and Pasture Science, Faculty of Science and Agriculture, University of Fort Hare, \\ Private Bag X1314, Alice, 5700, South Africa
}

(Received 31 July 2014; Accepted 7 April 2015; First published online 1 August 2015)

\begin{abstract}
Copyright resides with the authors in terms of the Creative Commons Attribution 2.5 South African Licence.
See: http://creativecommons.org/licenses/by/2.5/za

Condition of use: The user may copy, distribute, transmit and adapt the work, but must recognise the authors and the South African Journal of Animal Science.
\end{abstract}

\begin{abstract}
In this study the associations between animal traits, carcass traits and carcass classification within cattle, sheep and pigs slaughtered in a high throughput abattoir were determined. Classes of carcasses from cattle, sheep and pigs delivered for slaughter at this abattoir were recorded and analysed. Significant associations were found between carcass classes and breeds of all livestock species. Of all the cattle delivered to the abattoir, the non-descript ones dominated the AB2 category while the Bonsmara and Brahman dominated the $C$ categories. Almost $70 \%$ of carcasses of the cattle delivered to the abattoir were in the $C$ classes. In the sheep, the dominant category was A2 with a percentage of $77 \%$, and the Dorper was the most dominant in this category. In pigs, the $\mathrm{P}$ class was the most dominant with about $50 \%$, and the Duroc $X$ Landrace cross dominated this category. However, significant associations between sex and carcass classes were only found in cattle. Warm carcass mass had significant associations with carcass classes of cattle and sheep only. It can be concluded that while associations between carcass classes and breeds were found in all species, associations between sex and carcasses were dependent on species.
\end{abstract}

Keywords: Livestock breeds, sex, warm carcass mass

${ }^{*}$ Corresponding author: vmuchenje@ufh.ac.za

\section{Introduction}

The carcass classification system was established in most meat producing countries in the early to middle 1900s (Strydom, 2011). It involves the allocation of a class code to carcasses, allowing consumers to select a carcass according to their own preferences (KZN DAEA, 2005). Fisher (2007) indicated that the classification system provides the advantage of having a common language to describe carcasses within a country thus improving marketing efficiency and transparency. Strydom (2011) reported that carcass classification systems are intended to describe the quality and meat yield of carcasses to the benefit of traders and consumers. However, it was further concluded that the criteria used in the classification systems gave limited descriptions of the quality related characteristics of the carcasses. This is mainly because the system only describes scores and measurements but does not allocate rank according to carcass quality (Strydom, 2011).

In South Africa for instance, data recorded for beef, mutton and pork classification includes scores for conformation with classes ( 1 - very flat, 2 - flat, 3 - medium, 4 - round and 5 - very round), fatness $(0-$ no fat, 1 - very lean, 2 - lean, 3 - medium, 4 - fat, 5 - slightly overfat and 6 - extremely overfat), sex (the carcass of a ram or a bull as well as of a hamel, a kapater or an ox showing signs of late castration of the AB-, B- or C-age classes are identified), bruising (1 - slight, 2 - moderate and 3 - severe) and age (0 teeth $A, 1-2$ teeth $-A B, 3-6$ teeth $-B$, more than 6 teeth - C). Age is, however, not considered in pork classification (SAMIC, 2006). These traits are based on visual examination of carcasses, with the only exception being the measurement of the subcutaneous fat on pig carcasses where a Hennessy grading apparatus is used (SAMIC, 2006).

Consumers on the other hand have strong preferences in relation to meat quality. They prefer the meat they consume to be tender, juicy, of good flavour, colour, aroma and to be safe and of good quality (Curtis et al., 2006). These characteristics are not visible to the consumer at the point of purchase and yet they tend to be neglected in the classification system. At present the point of contention in relation to the 
classification system is that quality is not ranked and consumers are not able to do this for themselves in retail outlets. If possible it would also provide quality assurance for different carcass classes.

According to a report by the Red Meat Industry Forum (RMIF) (2013), age and fatness are the most significant characteristics used in the classification system. The Food and Agriculture Organization (FAO, 2001) also indicated that body conformation might not have a direct impact on meat quality as it is only important when consumers want to select cuts based on preferences linked to the meat-to-bone ratio. Moreover, the main concerns associated with the sex characteristic are the higher prices that castrated male animals fetch, the better taste of their meat and the high fat content (FAO, 2000). Furthermore a study by Destefanis et al. (2003) proved that castration induces higher fat deposition and lower water content in muscle. Litwinczuk et al. (2006) and Zhang et al. (2006) reported that meat from heifers has significantly higher fat content than meat from bulls. It has also been reported that meat from intact males and castrated males have higher protein and ash contents than females, with intact males also having higher muscle development than castrated males. Nonetheless, they have lower fat deposition than castrated males. It has been indicated that the damage characteristic in the classification system is only used when part of the carcass contains bruises after slaughtering and the specific part is usually trimmed off (RMIF, 2013). However, the appearance of the untrimmed parts of a damaged carcass can deteriorate and serve as a growth medium for microorganisms causing the meat to spoil more rapidly than normal (Adziety, 2011). According to the FAO (2001), spoiled meat develops colour change, off-smells, rancidity and slime which can make consumers ill.

Although the classification system allocates scores on the extremes of these characteristics (age, sex, bruising, fat and conformation) it does not rank for the quality to be expected from each of the carcass classes exhibiting such extremes. This can prove problematic for consumers because they do not know what type of quality they are paying for in a specific class. Moreover animal traits such as breed are not included in the classification system. Breed has been proven to affect carcass and meat quality (Juárez et al., 2009). In addition, carcass traits such as warm carcass mass (WCM) are significant for the determination of lean and fat carcasses through dressing percentage (Knight, 2013). This therefore suggests that associations should be tested between animal traits such as breed, carcass traits such as warm carcass mass (WCM) and carcass classes in the classification system. The objective of this study was, therefore, to determine the associations between animal traits, carcass traits and carcass classes within cattle, sheep and pigs that were slaughtered in a high throughput abattoir.

\section{Materials and Methods}

The study was conducted at a selected high throughput abattoir in the Eastern Cape Province of South Africa. The abattoir slaughters up to 1000 livestock units per day. Data was collected from 100 cattle, 100 sheep and 100 pigs that were slaughtered within a week, but on different days at this abattoir. Six cattle breeds (Bonsmara, Brahman, Simmental, Friesland, Jersey and non-descript), three different sheep breeds (Dorper, Blackhead Persian and Merino) and two pig breeds (Duroc X Large White (DuroLarge) crosses and Duroc X Landrace (DuroLand) crosses) were studied. All the animals used in the study were delivered from different farms. The animals were observed during offloading at the abattoir and farm identity numbers were recorded. Animals were then followed through the slaughter floor where initially breed and sex were recorded before slaughter and thereafter age was recorded using the dentition method. Carcasses were further followed up to the point where they were classified and warm carcass mass and carcass classes were recorded. Data were analysed using the Statistical Analysis Systems (SAS) package of 2009. Frequency procedure (PROC FREQ) and Chi-square tests were used to examine the relationships between the animal traits, carcass traits and carcass classes. Statistical significance was tested at the $95 \%$ level with all findings with $P$-value $<0.05$ considered to be statistically significant.

\section{Results and Discussion}

A similar trend was observed in WCM of all three livestock species tested. There were fewer animals of high WCM than of low WCM in all the livestock species tested, with ranges (1\% - 4\%; $1 \%-5 \%$ and $24 \%)$ for cattle, sheep and pigs, respectively (Figures 1, 2 and 3). Warm carcass mass can be used to determine the dressing percentage of animals and it has been reported that heavier animals result in higher returns which may be attributed to the fact that they have more muscles than fat and are thus leaner (Knight, 2013). Lean meat is said to be generally preferred in the market and therefore fetches higher premiums. Since WCM has also been proven to have an influence on carcass quality traits such as lean-fat ratio, this therefore suggests that if WCM was included in the South African classification system, most farmers slaughtering their animals in this abattoir would be receiving low premiums as they are producing animals of low WCM with less lean meat. Therefore, WCM could motivate farmers to produce animals of high weights 
thus improving carcass quality traits such as the lean-to fat ratio. In addition dressing percentage with heavier breeds would produce more muscle and more lean meat per carcass (Knight, 2013).

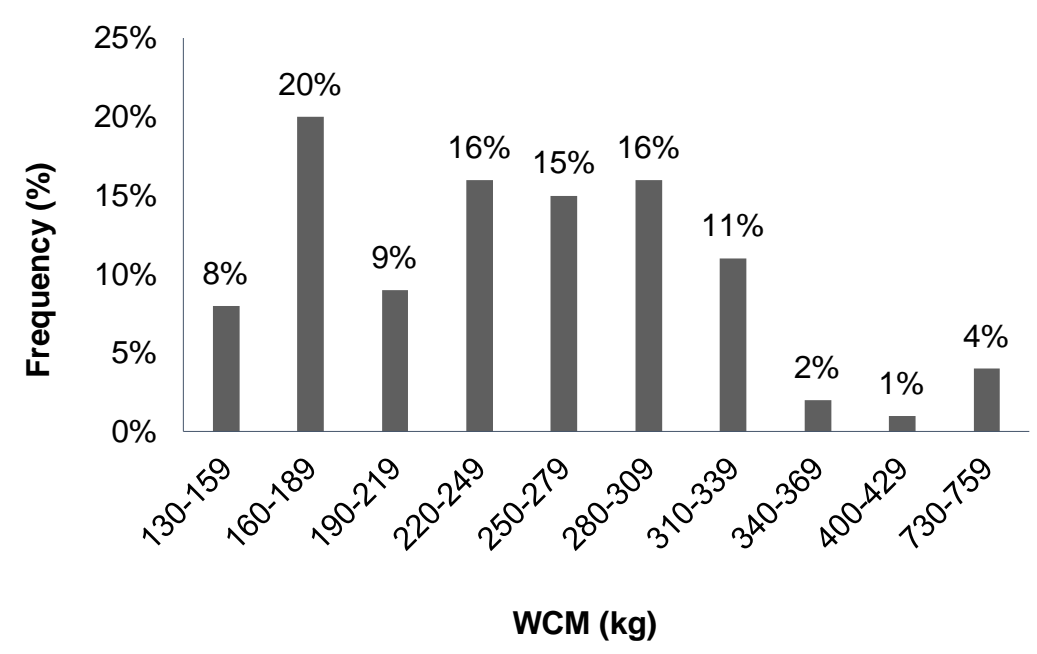

Figure 1 Warm carcass mass (WCM) of cattle slaughtered at the abattoir.

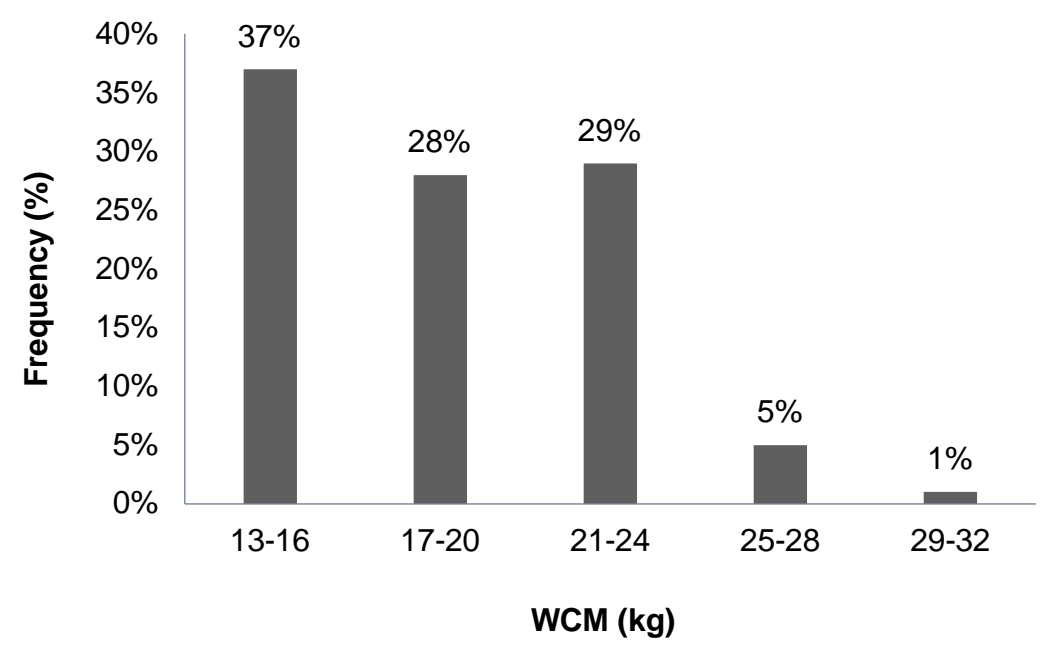

Figure 2 Warm carcass mass (WCM) of sheep slaughtered at the abattoir.

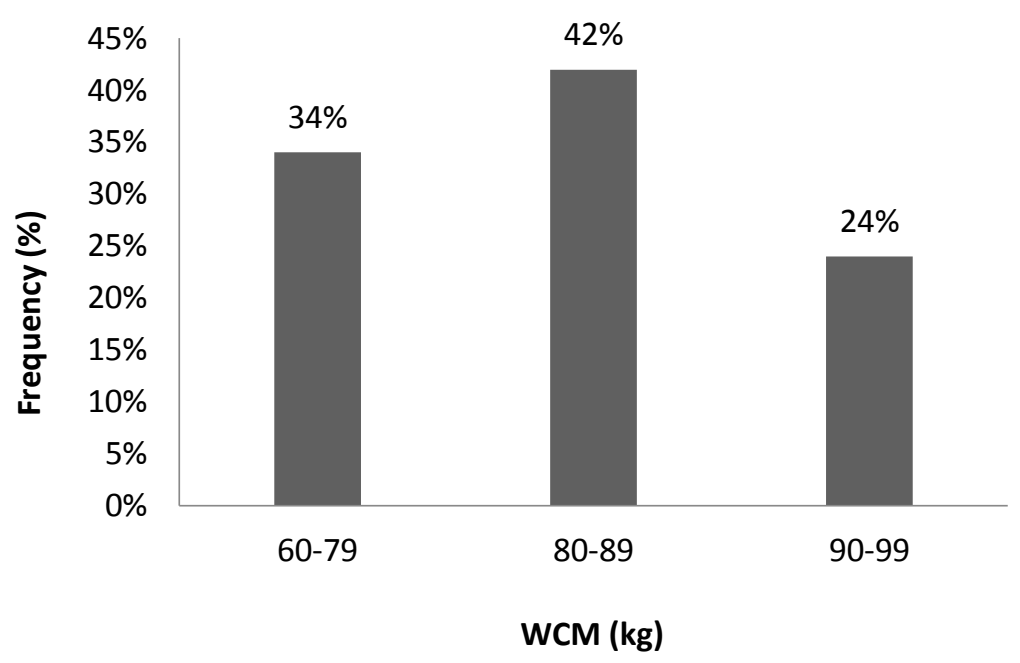

Figure $\mathbf{3}$ Warm carcass mass (WCM) of pigs slaughtered at the abattoir. 
Figure 4 shows that most of the farmers predominantly produce the Bonsmara breed followed by nondescript breeds with the least common breed being the Simmental. The Bonsmara breed dominates the feedlot industry and the Simmental breed also plays a major role in the industry. In contrast, the non-descript breeds dominate the emerging sector in South Africa (Scholtz et al., 2008). The Bonsmara breed is well recognised for being well muscled with high meat yield and quality (Muchenje et al., 2008). Dairy cattle on the other hand are intended for milk production which can influence their carcass quality traits (lean-to-fat ratio, dressing percentage and conformation) and consequently their meat quality traits (taste, colour and texture). However, at this abattoir it was mentioned that farmers raise dairy cattle specifically for beef production. There is a need to investigate the reasons for such a practice and to also determine the quality of meat from these dairy breeds that are reared to only produce meat. Moreover, research also needs to be done on meat quality of non-descript breeds which are common in the emerging livestock sector.

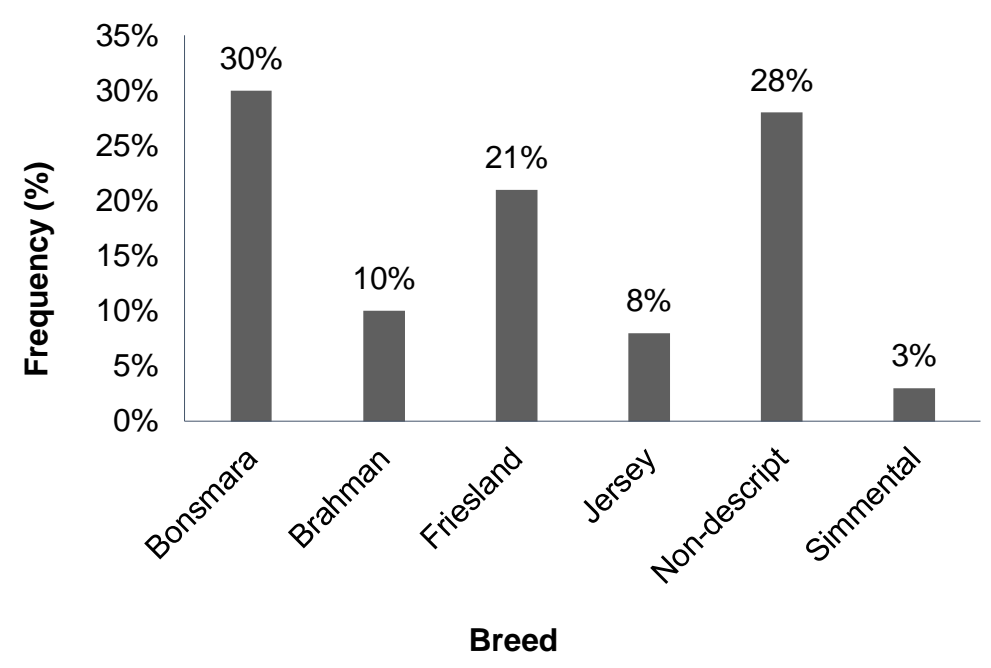

Figure 4 Cattle breeds slaughtered at the abattoir.

Figure 5 shows that most of the farmers produce cattle of the C-age class. Meat from the C-class animals is classified as meat from very old animals with low tenderness (SAMIC, 2006). Consequently these cattle fetch lower premium bonuses because of their age classification. The C-class was mostly dominated by the Bonsmara breed and particularly the C2-class. According to SAMIC (2006) a score of 2 in the fat class is classified as lean meat, thus the fat content in the C2-class is low, giving an advantage of high premium bonuses to these farmers because consumers prefer lean meat.

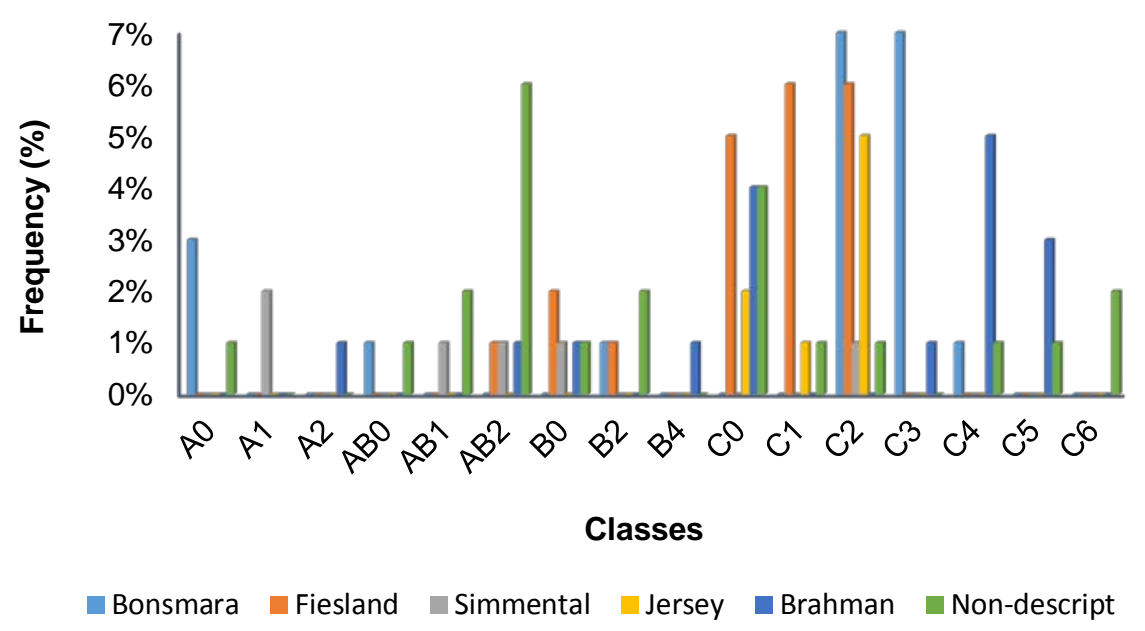

Figure 5 Carcass classes produced per cattle breed. 
Figure 6 shows that a very low percentage (7\%) of farmers produces beef carcasses of the A-class while a large percentage (69\%) produces cattle of the C-class. The percentages of $A B$ - and B-classes on the other hand are in between the A- and C-classes with percentages of $14 \%$ and $10 \%$, respectively. The dominant fat score was $2(39 \%)$ which is classified as lean meat which is generally preferred in the market.

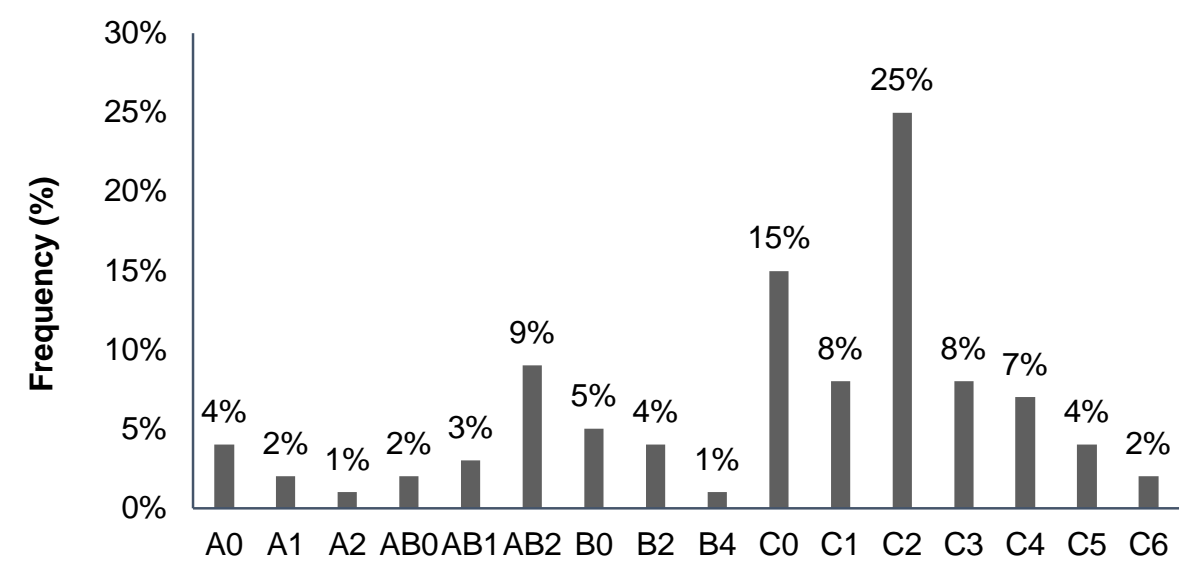

Classes

Figure 6 Carcass classes of cattle slaughtered at the abattoir.

Figure 7 shows that most farmers produce the Dorper sheep breed with Blackhead Persian being the least preferred. Different sheep breeds have been reported to have different carcass quality traits (Hanrahan, 1999) and thus also different meat quality traits (Tshabalala et al., 2003).

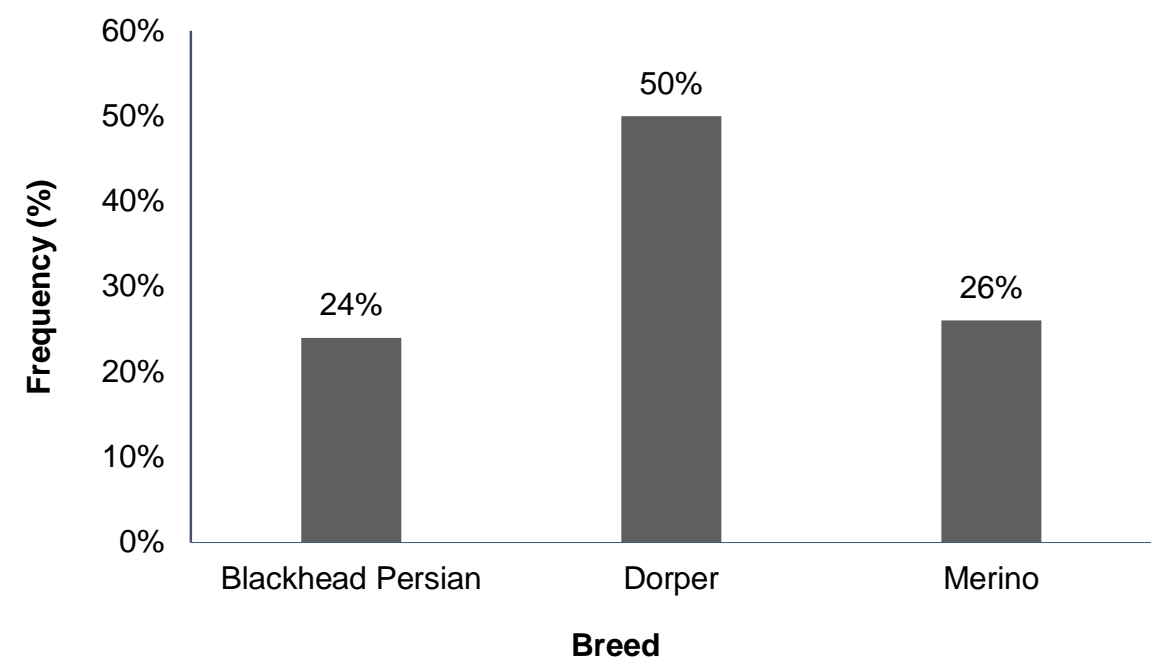

Figure 7 Sheep breeds slaughtered at the abattoir.

Figure 8 shows that most sheep farmers produce mutton carcasses of the A-age class particularly the A2-class (77\%). The A2-class is the most desirable class in South Africa as it is classified as meat from a very young animal which is most tender and lean. The Dorper breed dominated the A2-class (38\%). Nonetheless, the Merino and Blackhead Persian were also dominant in the A2-class compared to other classes. 


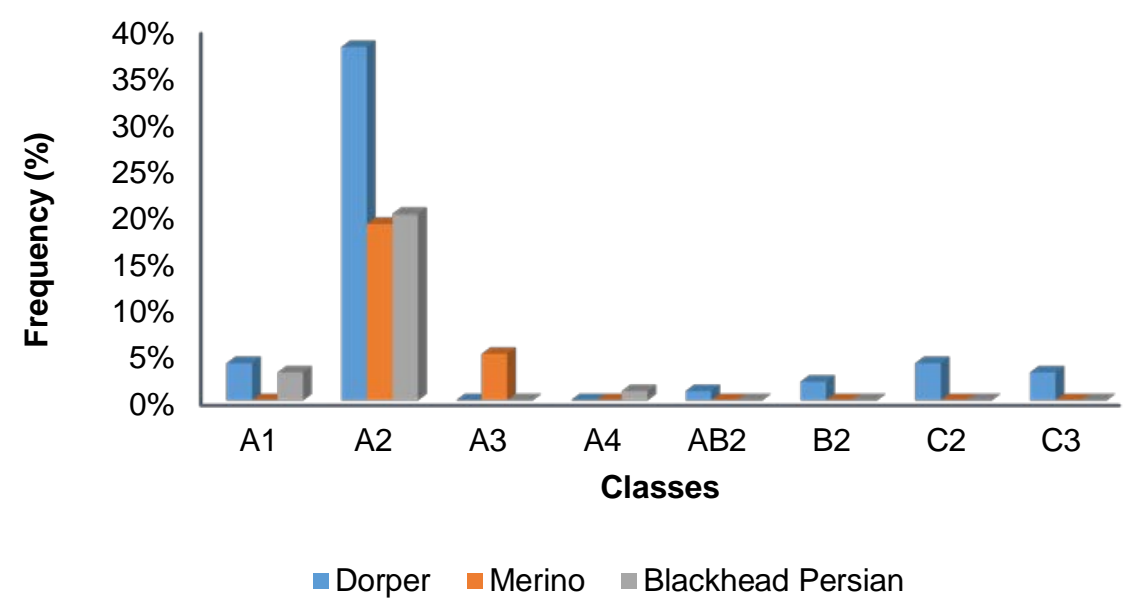

Figure 8 Carcass classes produced per sheep breed.

Figure 9 shows that a very low percentage (1\%) of farmers produces mutton carcasses of the AB-class while a large percentage (91\%) produces carcasses of the A-class. The B-and C-classes are in between the $A$ - and the $A B$-classes with percentages of $2 \%$ and $8 \%$, respectively. The dominant fat score was $2(80 \%)$ which is classified as lean meat which is generally preferred in the market. Thus most farmers are producing lean mutton.

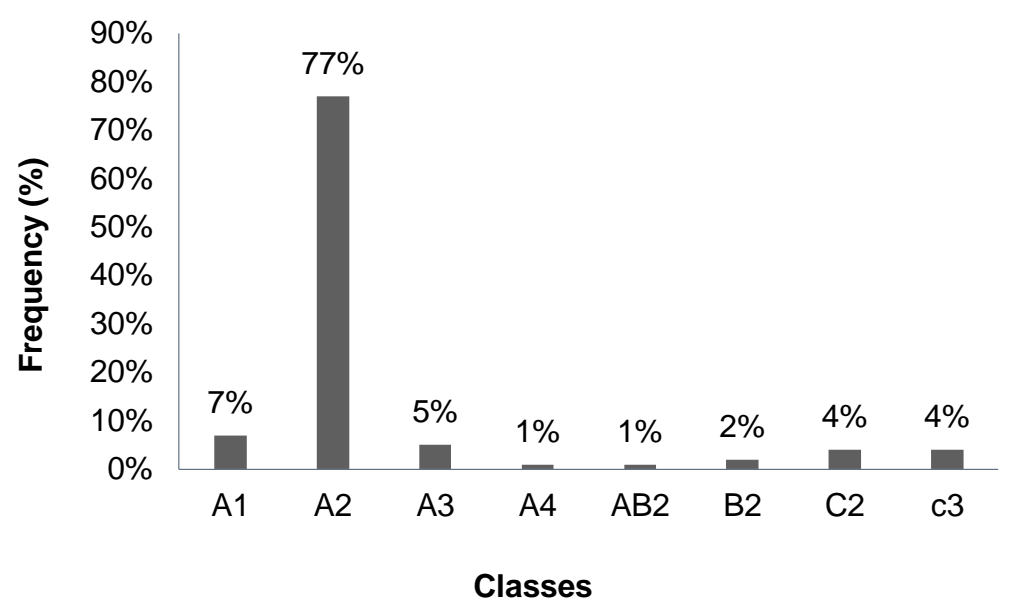

Figure 9 Carcass classes of sheep slaughtered at the abattoir.

Figure 10 shows that most pig farmers produced Duroc $X$ Large White crosses (54\%). Ryu et al. (2008) indicated that different pig breeds have different carcass and meat quality traits.

Figure 11 shows that the pig farmers mostly produced the P-class with a percentage of $49 \%$. As reported (Strydom, 2011), age and fat are the most important characteristics used in the SA classification system. No rankings are made in terms of age in pork classification. The P-class which is classified as a carcass with $70 \%$ and more meat and $(1 \mathrm{~mm} \geq$ subcutaneous fat thickness $\leq 12 \mathrm{~mm}$ ), was mostly dominated by the Duroc $X$ Landrace crosses. The Duroc $X$ Large White crosses dominated the O-class which is classified as a carcass with $(68 \leq$ Meat $\% \leq 69)$ and $(12 \mathrm{~mm} \leq$ subcutaneous fat thickness $\leq 17 \mathrm{~mm})$. Few (7\%) Duroc X Large White crosses dominated the R-class which is classified as $(66 \leq$ Meat $\% \leq 67)$ and $(17 \leq$ subcutaneous fat thickness $\leq 22 \mathrm{~mm}$ ). 


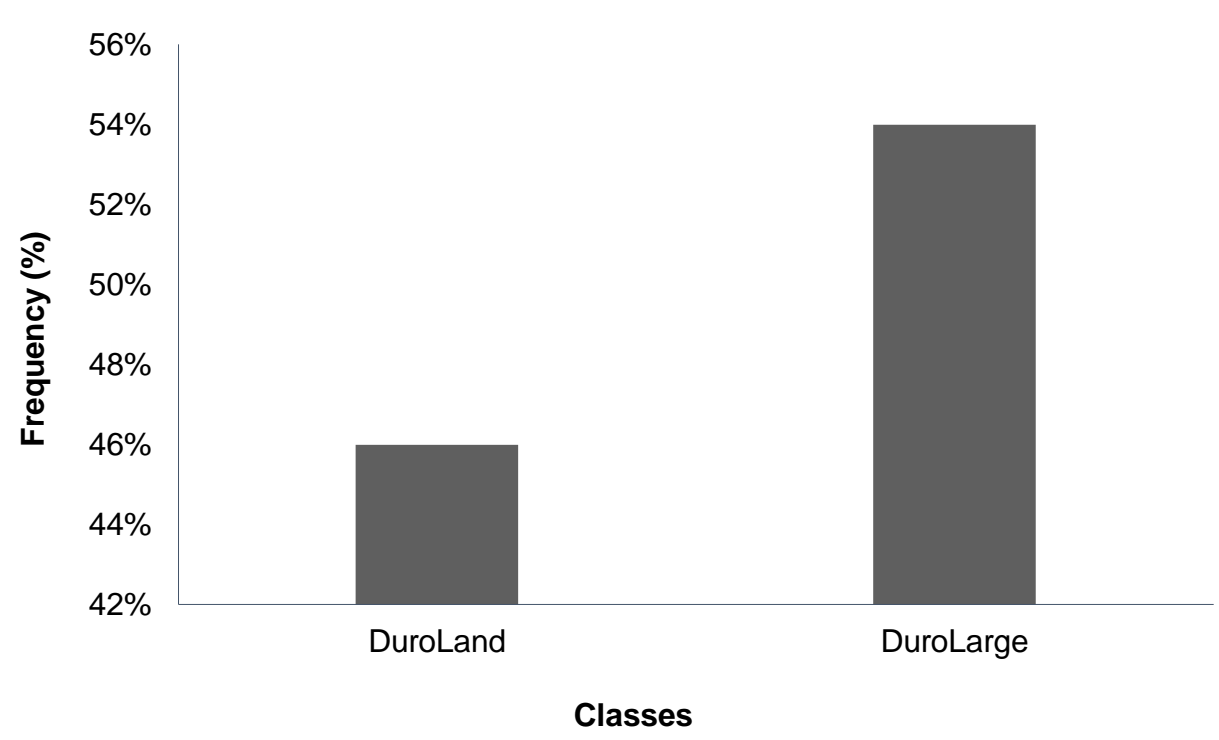

Figure 10 Pig breeds slaughtered at the abattoir.

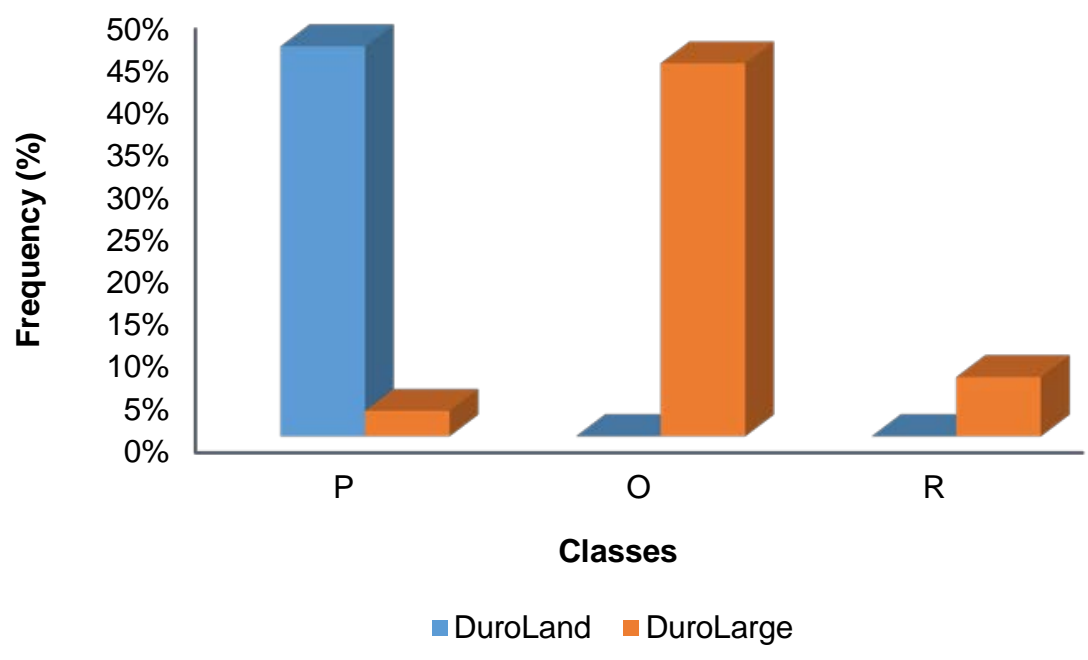

Figure 11 Carcass classes produced per pig breed.

Figure 12 shows that the most produced pork class is the P-class (49\%). However, a large percentage (44\%) also falls in the O-class and the R-class is the least produced. This may be attributed to the fact that these classes are preferred in the order of $\mathrm{P}, \mathrm{O}, \mathrm{R}, \mathrm{C}, \mathrm{U}, \mathrm{S}$; thus producers produce pork classes with the highest preference ratings, as to be expected.

Figure 13 shows that most of the cattle that were delivered to this abattoir were cows (56\%) while $26 \%$ were castrated cattle. The least delivered were heifers (9\%) and bulls (9\%). However, castrated animals have been reported to have good carcass and meat quality traits (Destefanis et al., 2003; Litwinczuk et al., 2006; Zhang et al., 2010). Figure 14 shows that more rams/male castrates than ewes were slaughtered at this abattoir. However, more sows than boars were slaughtered (Figure 15). This could be due to the fact that the farmers try to avoid boar taint which has a negative effect on pork quality. 


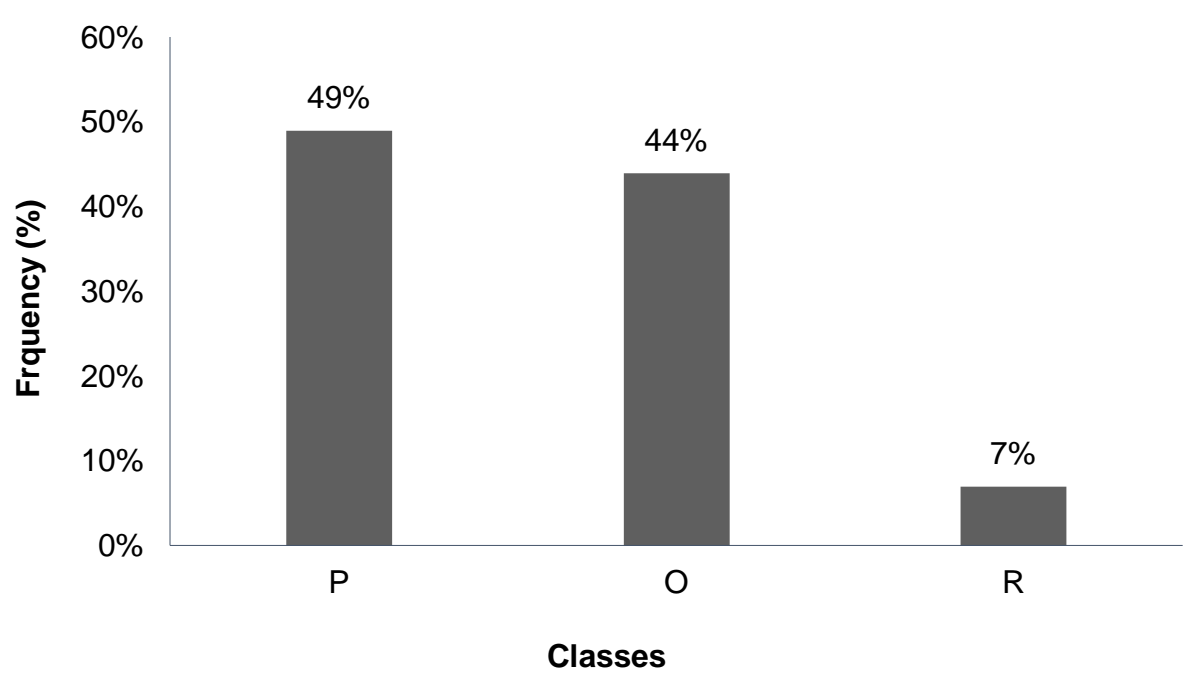

Figure 12 Pork carcass classes produced at the abattoir.

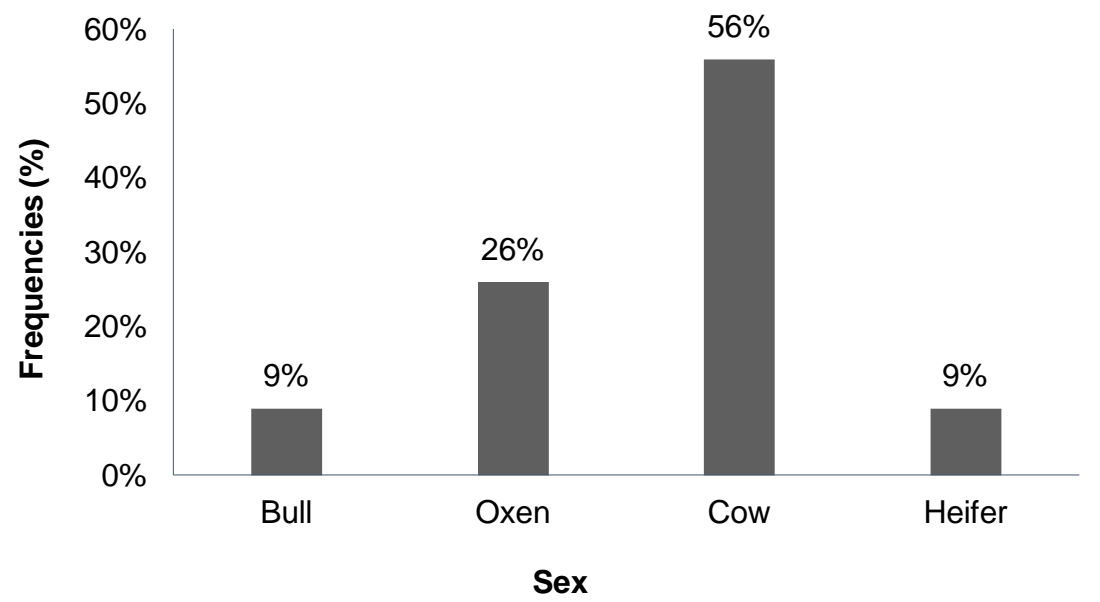

Figure 13 Sex of cattle slaughtered at the abattoir.

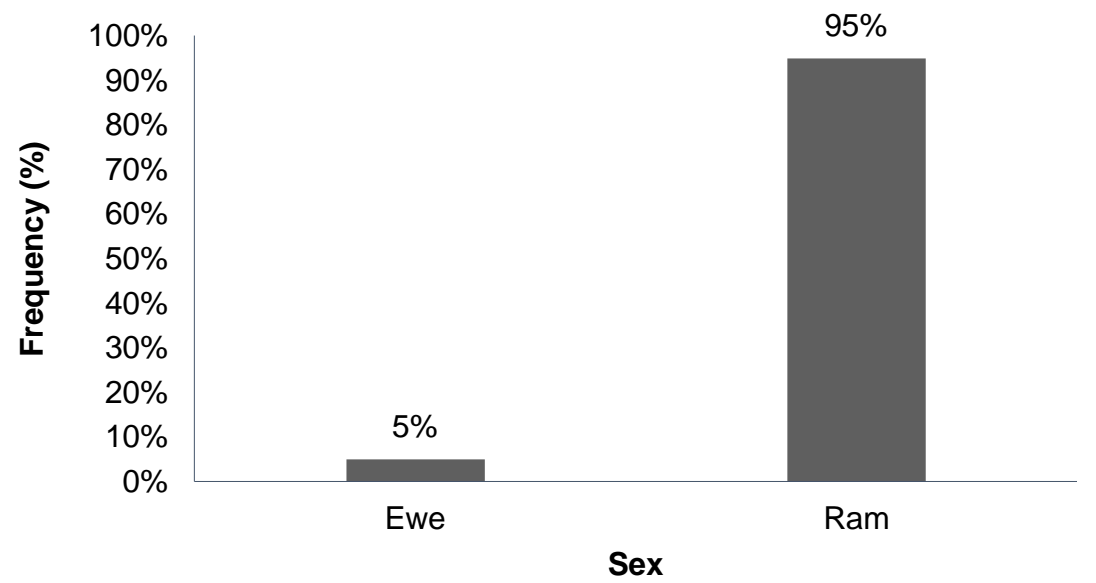

Figure 14 Sex of sheep slaughtered at the abattoir. 


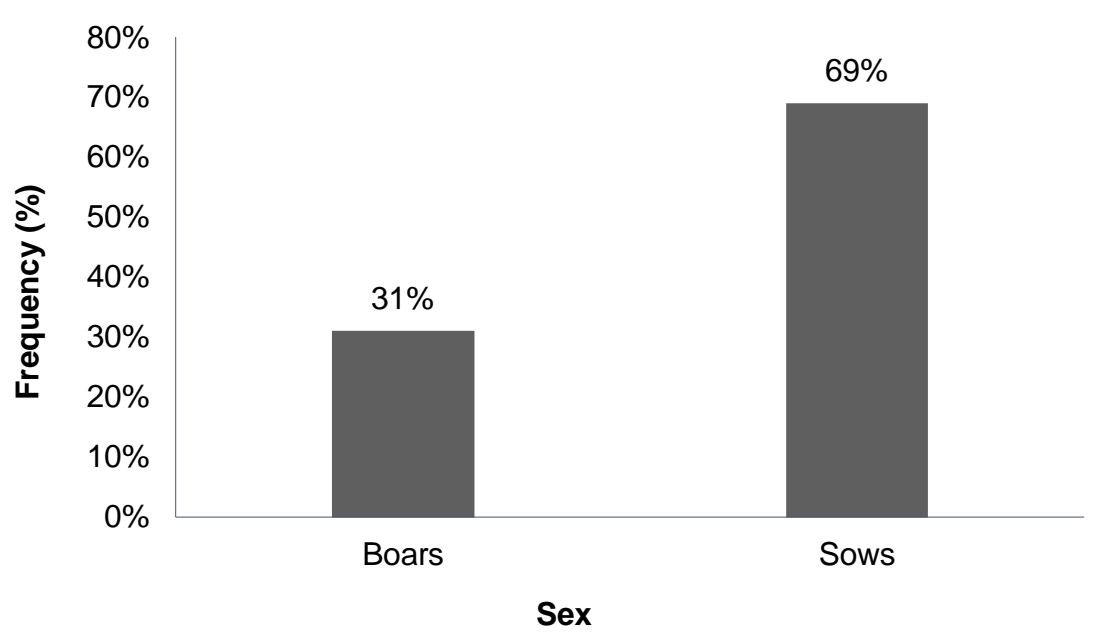

Figure 15 Sex of pigs slaughtered at the abattoir.

The results in Table 1 show that there was an association $(P<0.001)$ between class and sex of cattle, but in sheep and pigs there was no association between the two variables $(P>0.05)$. According to Destefanis et al. (2003), Litwinczuki et al. (2006) and Zhang et al. (2010), sex has an effect on various meat quality attributes such as muscle chemical composition, fat deposition, protein and ash content. Therefore, research needs to be conducted on the interactions between sex and carcass classes of all red meat producing livestock species to provide the carcass quality exhibited by the sex characteristic in each class.

Table 2 shows that there were significant breed by class associations in carcasses from cattle, sheep and pigs. Associations between sheep breeds and carcass quality have been reported in the study by Shackelford et al. (2012) which showed that progeny of Suffolk sires were heavier than progeny of other breeds. This was also evident from the carcass weights and the 12th rib fat percentage which was greater for Dorper progeny than those of other breeds, except White Dorper and Katahdin. The study further indicated that Finnsheep and Romanov sires had a greater percentage of intramuscular fat and also achieved greater marbling scores than the other breeds. Such results comprehensively show that breed diversity has an effect on some carcass characteristics and consequently also on sheep carcass classes. Sheep with better marbling or intra-muscular fat should thus have better carcass classes since marbling improves meat tenderness, juiciness and aroma (Curtis et al., 2006). The marbling factor is, however, not considered in the SA classification system. Therefore, more research still needs to be done on the relationships between breed and carcass classes across all red meat producing species. Rankings should be made based on the carcass quality attributes of each class in a specific breed and marbling scores and the relationship between these two variables should perhaps be considered.

Table 1 Associations between sex and the A-, AB-, B- and C-carcass classes in cattle and sheep, and $\mathrm{P}_{-}, \mathrm{O}-$-, and R-carcass classes in pigs

\begin{tabular}{lrrl}
\hline Species & Chi value & $P$-value & Association \\
\hline Cattle & 193.192 & $<0.001$ & $*$ \\
Sheep & 4.201 & 0.756 & NS \\
Pig & 3.942 & 0.139 & NS
\end{tabular}

* Significant association $(P<0.001)$; NS: No significant association $(P>0.05)$.

Table 3 shows that there were associations between WCM and carcass class $(P>0.05)$ in sheep and cattle while there was no association between the two variables in pig carcasses. This variation calls for more research on the possible relationships between carcass weights and classes within livestock species from different production systems. Since Knight (2013) found that heavier animals result in higher returns 
because they have more muscle/flesh than fat and are therefore leaner, studies integrating carcass classification with different species weights should be carried out.

Table 2 Associations between breed and the A-, AB-, B-, and C-carcass classes in cattle and sheep and P-, O-, and R-carcass classes in pigs

\begin{tabular}{lrrr}
\hline Species & Chi value & P-value & Association \\
\hline Cattle & 131.142 & $<0.0001$ & $*$ \\
Sheep & 118.641 & $<0.0001$ & $*$ \\
Pig & 88.993 & $<0.0001$ & $*$ \\
\hline
\end{tabular}

* Significant association $(P<0.001)$.

Table 3 Associations between warm carcass mass (WCM) and the A-, AB-, B-, and $\mathrm{C}$-carcass classes in cattle and sheep and $\mathrm{P}_{-}, \mathrm{O}-$, and R-carcass classes in pigs

\begin{tabular}{lccc}
\hline Species & Chi value & $P$-value & Association \\
\hline Cattle & 1330.413 & 0.0458 & $*$ \\
Sheep & 627.529 & $<.0001$ & $*$ \\
Pig & 141.272 & 0.3609 & NS
\end{tabular}

**Significant association $(P<0.001) ; *(P<0.05)$; NS: No significant associations.

\section{Conclusion}

Associations were found between breed and carcass classes of cattle, sheep and pigs. Sex was only found to be associated with all carcass classes in cattle. Significant associations were also found between WCM and carcass classes of cattle and sheep. No associations were found between carcass classes and WCM of pigs. The results from this study suggest that animal traits such as breed and carcass traits such as WCM affect carcass classes. More research should therefore be done on the relationship between the breed, WCM and the A-, AB-, B- and C-classes in sheep and cattle and P-, O- and R-classes in pigs.

\section{Acknowledgements}

The authors wish to thank the management and staff of the participating abattoirs. This study was sponsored by the National Research Foundation (NRF) Research and Technology Fund (RTF) Grant and the NRF South Africa-Namibia Collaboration Project. Our sincere gratitude is also extended to all the technical staff of the Department of Livestock and Pasture Science (University of Fort Hare).

\section{References}

Adzitey, F., 2011. Effect of pre-slaughter animal handling on carcass and meat quality. Int. Food Res. J. 18, 484-487.

Curtis, K., Cowee, M., Acasta, W., Hu, S., Lewis, S. \& Harris, T., 2006. Consumer preferences for meat attributes. University of Nevada, USA.

Destefanis, G., Brugiapaglia, A., Barge, M.T. \& Lazzaroni, C., 2003. Effect of castration on meat quality in Piemontese. Meat Sci. 64, 215-218.

FAO, 2000. Red Meat Marketing. Paper No.7 on Livestock marketing. Retrieved on 04 March 2014 from http://www.nda.agric.za/docs/GenPub/7livestock.pdf

FAO, 2001. Guidelines for humane handling, transport and slaughter of livestock. Chapter 6: Transport of livestock. Retrieved on 01 October 2013 from www.fao.org.

Fisher, A., 2007. Beef carcass classification in the EU: An historical perspective. In: Evaluation of carcass and meat quality in cattle and sheep. EAAP Publication No. 123 (Eds: Lazzaroni, C., Gigli, S. \& Gabina, D., Wageningen Academic Publishers, Netherlands, Wageningen, Gelderland. pp.19-30. 
Hanrahan J.P., 1999. Genetic and non-genetic factors affecting lamb growth and carcass quality. End project Reports: Sheep series, 8, Teagasc Research Centre. ISBN: 1841700622.

Juárez, M., Pollvilo, O., Gómez, M.D., Alcalde, M.J., Romeo, F. \& Valera, M., 2009. Breed effect on carcass and meat quality of foals slaughtered 24 months of age. Meat Sci. 83, 224-228.

Knight, C.H., 2013. Understanding beef carcass reports. University of Georgia and Ft Valley State University, US. Retrieved on 18 August 2014 from www.ugaext.gov.za

KZN DAEA, 2005. The beef carcass classification system. Retrieved on 04 March 2014 from www.agriculture.kzntl.gov

Litwinczuk, Z., Florek, M. \& Pietraszek, K., 2006. Physico-chemical quality of meat from heifers and young bulls of the black and white (BW) variety of Polish Holstein-Friesian breed and commercial BW crossbreds sired by Limousine and Charolais bulls. Anim. Sci. Pap. Rep. 24, 179-186.

Muchenje, V., Dzama, K., Chimonyo, M., Raats, J.G. \& Strydom, P.E., 2008. Tick susceptibility and its effects on growth performance and carcass characteristics of Nguni, Bonsmara and Angus steers raised on natural pasture. Animal 2, 298-304.

RMIF, 2013. Classification of South African beef - A key to consumer satisfaction. Retrieved on 7 March 2014 from www.redmeatsa.co.za

Ryu, Y.C., Choi, Y.M., Lee, S.H., Shin, H.G., Choe, J.H., Kim, J.M., Hong, K.C. \& Kim, B.C., 2008. The histochemical characteristics and meat quality traits of different pig breeds. Meat Sci. 80, 363-369.

SAMIC, 2006. Classification of red meat. Retrieved on 12 July 2014 from www.samic.co.za

SAS, 2009. Statistical Analysis Systems, Users' Guide. (5th ed.) (Version 9.2). SAS Institute Inc., Cary, N.C., USA.

Scholtz, M.M., Bester, J., Mamabolo, J.M. \& Ramsay, K.A., 2008. Results of the national cattle survey undertaken in South Africa, with emphasis on beef. Appl. Anim. Husb. Rural Dev. 1, 2-8.

Shackelford, S.D., Leymaster, K.A., Wheeler, T.L. \& Koohmaraie, M., 2012. Effects of breed of sire on carcass composition and sensory traits of lamb. J. Anim. Sci. 90, 4131-4139.

Strydom, P.E., 2011. Quality related principles of the South African beef classification system in relation to grading and classification systems of the world. S. Afr. J. Anim. Sci. 41, 177-194.

Tshabalala, P.A., Strydom, P.E., Webb, E.C. \& deCock, H.C., 2003. Meat quality of designated South African indigenous goat and sheep breeds. Meat Sci. 65, 563-570.

Zhang, Y.Y., Zan, L.S., Wan, H.B., Xin, Y.P., Adoligbe, C.M. \& Ujan, J.A., 2010. Effect of sex on meat quality characteristics of Qinchuan cattle. Afr. J. Biotechnol. 9, 4504-4509. 